\title{
ARTICLE OPEN The trimeric autotransporter adhesin BadA is required for in vitro biofilm formation by Bartonella henselae
}

\author{
Udoka Okaro ${ }^{1}$, Ryan Green ${ }^{1}$, Subhra Mohapatra ${ }^{1}$ and Burt Anderson ${ }^{1}$
}

Bartonella henselae $(\mathrm{Bh})$ is a Gram-negative rod transmitted to humans by a scratch from the common house cat. Infection of humans with $B h$ can result in a range of clinical diseases including lymphadenopathy observed in cat-scratch disease and more serious disease from persistent bacteremia. It is a common cause of blood-culture negative endocarditis as the bacterium is capable of growing as aggregates, and forming biofilms on infected native and prosthetic heart valves. The aggregative growth requires a trimeric autotransporter adhesin (TAA) called Bartonella adhesin A (BadA). TAAs are found in all Bartonella species and many other Gram-negative bacteria. Using Bh Houston-1, Bh Houston-1 $\Delta b a d A$ and Bh Houston-1 $\triangle b a d A / p N S 2 \mathrm{P}_{\text {Trc }} b a d A$ (a partial complement of badA coding for a truncated protein of 741 amino acid residues), we analyze the role of BadA in adhesion and biofilm formation. We also investigate the role of environmental factors such as temperature on badA expression and biofilm formation. Real-time cell adhesion monitoring and electron microscopy show that Bh Houston-1 adheres and forms biofilm more efficiently than the Bh Houston-1 $\triangle b a d A$. Deletion of the badA gene significantly decreases adhesion, the first step in biofilm formation in vitro, which is partially restored in Bh Houston-1 $\triangle b a d A / p N S 2 \mathrm{P}_{\text {Trc }}$ badA. The biofilm formed by Bh Houston-1 includes polysaccharides, proteins, and DNA components and is susceptible to enzymatic degradation of these components. Furthermore, both pH and temperature influence both badA expression and biofilm formation. We conclude that BadA is required for optimal adhesion, agglutination and biofilm formation.

npj Biofilms and Microbiomes (2019)5:10; https://doi.org/10.1038/s41522-019-0083-8

\section{INTRODUCTION}

Trimeric autotransporter adhesins (TAAs) are outer membrane proteins found on Gram-negative bacteria and shown to be involved in bacterial auto-agglutination as well as facilitating adhesion to extracellular matrix components and host cells. ${ }^{1}$ TAAs are characterized by the presence of an $\mathrm{N}$-terminal head which mediates adhesion to host cells, a repeating neck-stalk region and a C-terminal membrane anchor. ${ }^{2}$ TAAs have been studied extensively in other Gram-negative bacteria and shown to play a role in adhesion and biofilm formation., ${ }^{3,4}$ Bartonella adhesin $A$ $(\operatorname{Bad} A)$ is the TAA found in Bartonella henselae $(B h)$, and the longest known protein in the TAA family at $328 \mathrm{kDa}$ per monomer ( 1 million Daltons/trimer) forming filaments reported to be as long as $240 \mathrm{~nm}$ on the surface of $B h^{5}$

$B h$ is a Gram-negative, facultative intracellular zoonotic pathogen able to grow as auto-adherent aggregates or as non-adherent individual bacilli. ${ }^{6}$ Its native host is the cat, and it is transmitted by the cat flea (Ctenocephalides felis). ${ }^{7}$ Out of 45 known spp. in the Bartonella genus, 13 are known to cause human infection. While the cat is the predominant host for Bh, other Bartonella species have been isolated from a range of other mammals as reviewed in Okaro et al. ${ }^{8}$ In the case of $B h$, humans become infected through a scratch from an infected cat causing cat scratch disease (CSD)-a condition characterized by self-limiting lymphadenopathy. ${ }^{9}$ Annually, CSD affects about 24,000 people in the United States. ${ }^{10}$ Infection with $B h$ may also include fever with bacteremia, bacillary angiotomasis, bacillary peliosis and in some infected individuals,
$B h$ infections may progress to blood-culture-negative endocarditis BCNE. ${ }^{11}$

Two major virulence factors, BadA, and a type IV secretion system, VirB/T4SS, have been shown to have a lead role in $B h$ pathogenesis. ${ }^{12} B h$ has been shown to induce a proangiogenic response in its host which has been attributed to BadA. ${ }^{13,14}$ BadA is also implicated in biofilm formation primarily because of its attachment and adherent properties, and expression levels of badA have been shown to correlate with biofilm formation. ${ }^{8,15}$ Because adhesion and aggregation are critical for biofilm formation, it is reasonable to expect that $\mathrm{BadA}$ is also required for optimal $B h$ biofilm formation.

Biofilms have been implicated in two distinct parts of the $B h$ life cycle. First, is the colonization and persistence in the arthropod vector. $B h$ is able to replicate in the cat flea, is excreted in flea feces and can be detected in both fleas and feces at least 12 days post-infection. ${ }^{16}$ The ability to persist through the formation of a biofilm very likely increases the efficiency of transmission from the flea to the vertebrate host. $B h$ is transmitted by infected flea feces spread to humans through the scratch of a cat. ${ }^{17}$ Secondly, Bh biofilms are also an important component of the heart valve vegetations observed in patients with BCNE as reviewed in Bjarnsholt (2013). ${ }^{18}$ At least six Bartonella species are associated with infectious endocarditis with $95 \%$ of all Bartonella cases involving either $B$. quintana or $B h$. The ability of $B h$ to form a stable biofilm contributes to its ability to persist in the host, often requiring surgical resection of the infected heart valve in patients with infective endocarditis. ${ }^{8}$

'Department of Molecular Medicine, Morsani College of Medicine, University of South Florida, Tampa, FL, USA

Correspondence: Burt Anderson (banderso@health.usf.edu)

Received: 9 November 2018 Accepted: 1 February 2019

Published online: 14 March 2019 


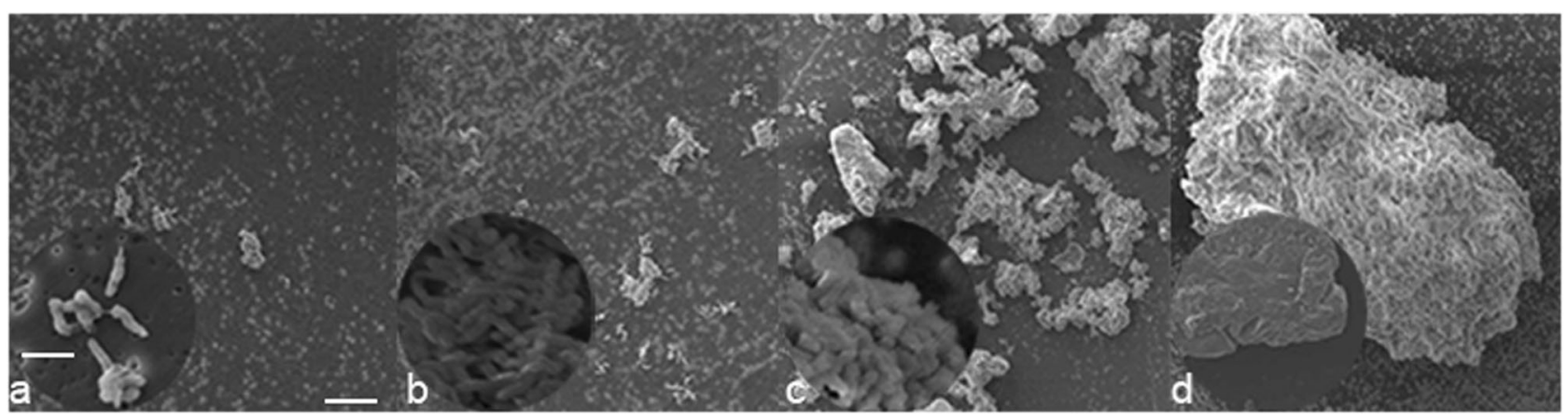

Fig. 1 Scanning electron micrograph showing adherence and biomass accumulation of the wild type parental Bh Houston strain. Bh growth from $8 \mathrm{~h}$ a, through $72 \mathrm{~h} \mathrm{~d}$. On Day 1, cells first attach a $(8 \mathrm{~h})$, before aggregation and production of micro-colonies $(24 \mathrm{~h}) \mathbf{b}$. The aggregates undergo tremendous growth at $48 \mathrm{~h}$ c and begin to produce a biofilm within $72 \mathrm{~h}$ d. Bacterial EPS was preserved by the addition of Alcian blue to the fixative. Scale bar: $20 \mu \mathrm{m}$, insert scale bar: $3 \mu \mathrm{m}$

\begin{tabular}{|ll}
\hline Table $1 . \quad$ Bacteria strains and primers used for this study & \\
\hline Bh Houston -1 & Regnery et al. 1992 \\
Bh Houston-1 $\Delta$ badA & Lima et al. 2014 \\
Bh Houston-1 $\Delta$ badA/pNS2P Trc $_{\text {badA }}$ & This study \\
E.coli DH $5 \alpha$ & Invitrogen \\
badAF1 & GCACGGATCCAGACTCAACACGCTCCC \\
badAR1 & AGCATTAATACCTGAAGCGGTG \\
badAF2 & CACCGCTTCAGGTATTAATGCTACGCATGTAGAGAATGGTGA \\
badAR2 & GCACTCTAGATTCGTAGAAACAAGAGACCAACTG \\
Screen $1 \mathrm{~F}$ & ACGCATGTAGAGAATGGTGA \\
Screen $1 \mathrm{R}$ & CTTCGCATCTTCAAGCACTATCT \\
\hline Underlined nucleotides show restriction sites &
\end{tabular}

In their natural environment, biofilms grow as 3-dimensional structures. To accurately model biofilm growth in vitro, we employed the use of a 3-dimensional nanofibrous scaffold previously used to grow tumor cells. ${ }^{19}$ Likewise, as a more reproducible and information-rich alternative to the traditional crystal violet assay, an xCELLigence Real-Time Cell Analysis (RTCA) system was used for monitoring biofilm dynamics continuously throughout the entire assay. In this system, adherence of bacteria to gold microelectrodes embedded in the bottom surface of xCELLigence microplates (e-Plates) impedes the flow of current between electrodes. This impedance signal, reported as cell index, provides a composite assessment of cell number, cell size, and cell-substrate attachment. ${ }^{20}$ As bacteria grow, the tight interaction between adhering cells begins to impede the flow of current. Importantly, neither the gold electrodes nor the weak electric field perturbs bacterial adhesion or growth.

In this report, we employ both conventional end-point analysis and real-time analysis to investigate the role of badA expression on biofilm formation. We also examined the components of the biofilm using $B h$ cultured on a 3-dimensional nanofibrous scaffold. Finally, we monitored the sensitivity of the biofilm to enzymes and various growth conditions to determine the optimum biofilm conditions for $B h$. We posit that the formation of such a biofilm by $B h$ represents the niche in which these bacteria persist in both the cat flea vector and vertebrate host.

\section{RESULTS}

$B h$ forms a biofilm

To examine biofilm formation by $B h$ Houston- $1,10^{6}$ bacteria in a $150 \mu \mathrm{l}$ volume were inoculated into a 96 well polystyrene plate with a nitrocellulose membrane on the bottom. The membrane was removed after $8-72 \mathrm{~h}$ incubation and processed to track the progression of biofilm formation. Scanning electron microscopy was used to observe biofilm formation by $B h$ Houston-1. Individual rods were observed to aggregate and form micro-colonies within $8 \mathrm{~h}$ of inoculation (Fig. 1a). These micro-colonies aggregate to form larger and more defined colonies observed $24 \mathrm{~h}$ post inoculation (Fig. 1b). Rapid growth and biofilm are observed $48 \mathrm{~h}$ after inoculation (Fig. 1c). At $72 \mathrm{~h}$ of growth, EPS surrounds the mature biofilm (Fig. 1d).

\section{Construction of a partial badA complement}

In order to complement and restore BadA function to our $\triangle b a d A$ mutant, we constructed a plasmid containing coding regions for specific functional domains of BadA, resulting in a truncated protein of 741 amino acids. (See supplementary fig. 1a). The resulting plasmid was transformed into $B h$ Houston- 1 yielding $B h$ Houston-1 $\triangle b a d A / p N S 2 \mathrm{P}_{\text {Trc }}$ badA. To assess transcription in this strain, qRT-PCR was used to show that the partial complement transcribes badA at levels approximately 10 -fold greater than the parental Houston 1 strain (see supplementary fig. 1b, badA primers: screen $1 \mathrm{~F}$ and $1 \mathrm{R}$ - Table 1). This high-level of transcription is due to the $P_{\text {trc }}$ promoter which we have previously shown is a very efficient promoter that is not repressed in $B h^{21}$ Conversely, BadA protein levels in the $B h$ Houston- $1 \Delta b a d A / p N S 2 P_{\text {Trc }}$ badA complemented strain are comparable to those of the parental strain as demonstrated by confocal microscopy on intact bacteria using an antibody specific to BadA (see supplementary fig. 2). The $B h$ Houston-1 parental strain, the $\triangle b a d A$ deletion mutant, and the $B h$ Houston-1 $\triangle b a d A / p N S 2 P_{\text {Trc }}$ badA complemented strain displayed comparable growth curves suggesting that badA 

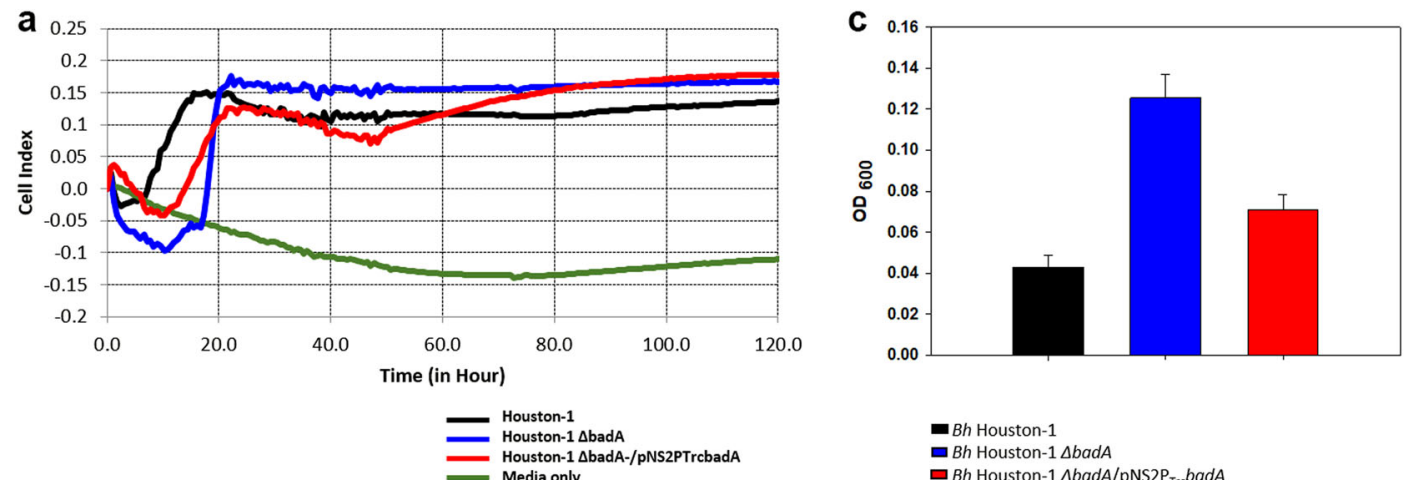

- Bh Houston-1

- $B$ h Houston-1 $\triangle b a d A$

- $B h$ Houston-1 $\triangle b a d A / p N S 2 P_{\text {Tre }}$ badA

b

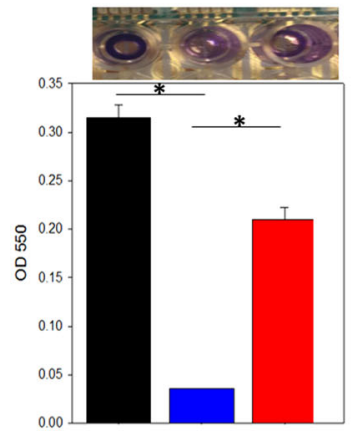

d

Houston-1

Houston-1 $\triangle b a d A$

Houston-1 $\triangle b a d A$ / pNS2PTrcbadA

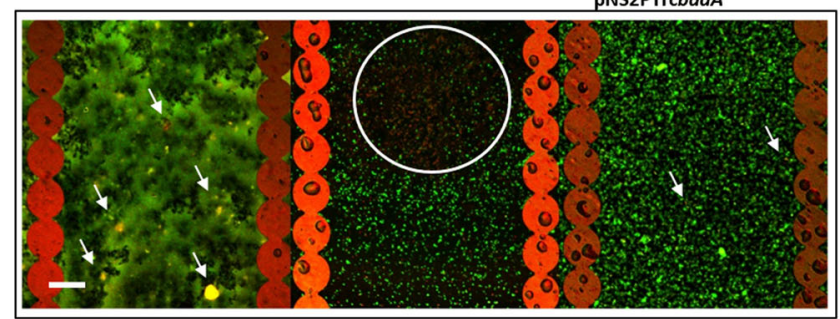

Fig. 2 Bh biofilm formation using a 96-well e-plate. The biofilm was grown on e-plates for 5 days, at $37^{\circ} \mathrm{C}$ and $5 \% \mathrm{CO}_{2}$, and stained with either $\mathrm{CV}$ for biomass or live/dead staining for biofilm cell viability. a Real-time cell index of Bh strains for 5 days. $\mathbf{b}$ Biomass from Bh cells using the eplate from experiment 2a stained with $0.1 \%$ CV $\left({ }^{*} P<0.05\right.$, Student's $t$-test). c The The density of each strain's supernatant aspirated from experiment $2 \mathrm{a}$ before staining with CV. d CLSM image of a Bh biofilm population using the STYO9/PI live/dead staining after 5 days of incubation (scale bar, $23 \mu \mathrm{m}$ ). Viability staining was used to determine the viability of bacterial cells within the EPS. White arrows depict cells with a partially disrupted membrane (yellow cells), and the white circle depicts the concentration of dead population (red cells). Error bars represent the standard error of the mean. Data set $(n=6)$

transcription levels and BadA protein synthesis are not a function of altered growth rate (see supplementary fig. 1c).

\section{BadA plays a major role in biofilm formation}

To assess $B h$ biofilm formation in real-time we employed the $x$ Celligence RTCA system. All three strains adhered to the plate to varying degrees and at differing times (Fig. 2a). The Houston-1 parental strain adhered more efficiently in the early stages of growth $(<20 \mathrm{~h})$ but the Bh Houston-1 $\triangle b a d A$ displayed a higher cell index $(\mathrm{Cl})$ statistically different from the Bh Houston-1 $(p<$ 0.001 , students $t$-test) at the end of the experiment $(120 \mathrm{~h})$. There was no significant difference between $B h$ Houston- $1 \triangle b a d A$ and $B h$ Houston- $1 \triangle b a d A /$ pNS2P $\mathrm{P}_{\mathrm{Tr}} b a d A$ ( $P=0.163$, students $t$-test) at that same time point. This prompted us to use microscopy and traditional endpoint biofilm assays to evaluate the $B h$ Houston- 1 $\triangle$ badA cells. Crystal violet (CV) stain of the biofilm on the e-plates post-real-time monitoring, shows that $B h$ Houston- 1 biofilm is statistically different from $B h$ Houston- $1 \Delta b a d A(p=0.004)$ but not significantly different from $B$ houston-1 $\triangle b a d A /$ pNS2P $\mathrm{P}_{\text {Trc }}$ badA $(P$ $=0.6$ ) (Fig. 2b). Partial complementation of badA in Bh Houston-1 $\triangle b a d A / p N S 2 \mathrm{P}_{\mathrm{Trc}}$ badA resulted in an intermediate level of biofilm formation (Fig. 2b). Despite the high cell index recording from the RTCA system at $120 \mathrm{~h}$, using the standard CV biofilm method, $B h$ Houston-1 $\triangle b a d A$ cells did not form as much biofilm compared to the BadA expressing strains. We also measured the cell density of the supernatant $\left(\mathrm{OD}_{600}\right)$ (Fig. $2 \mathrm{c}$ ) to determine how much of the $B h$ cells did not adhere to the e-plate. The Bh Houston-1 $\triangle b a d A$ supernatant was the least adherent, indicating that BadA is important for initial adherence of bacteria to the plate. Data from both the real-time analysis experiments and the CV staining confirm that BadA is required for optimal biofilm formation by $B h$.
The viability of $B h$ cells within a biofilm

To determine the viability of cells in the $B h$ biofilm, we utilized a two fluorescence cell viability kit containing SYTO9 green fluorescent nucleic acid stain and the red-fluorescent nucleic acid stain, propidium iodide (PI). Confocal laser scanning microscope (CLSM) was used to investigate the cells stained with SYTO9 and PI. SYTO9 stains nucleic acid hence it stains both live and dead cells but in the presence of PI, which penetrates disrupted membranes, the SYTO9 is displaced and the cell fluoresces yellow for partial SYTO9 displacement or red for complete displacement. Both Bh Houston-1 and Bh Houston-1 $\Delta b a d A / p N S 2 P_{\text {Trc }} b a d A$ cells growing in biofilms show more viable cells exhibiting green fluorescence and few dead cells with yellow fluorescence (Fig. 2d, white arrows). In contrast to the BadA expressing strains, the biofilm formed by $B h$ Houston- 1 bbadA sheltered a large population of dead cells (Fig. $2 \mathrm{~d}$, white circle).

\section{Components of the $B h$ biofilm}

The $B h$ Houston- 1 strain was used to characterize the biochemical composition of the biofilm. Scanning electron microscopy (SEM) was employed to examine images of the biofilm produced by $B h$ grown on a 3-dimensional nanofibrous scaffold. In Fig. 3 (top row, L-R), SEM images show scaffold only, Bh Houston-1, Bh Houston-1 $\triangle b a d A$ and Bh Houston-1 $\triangle b a d A / p N S 2 \mathrm{P}_{\text {Trc }}$ badA cultured on the scaffold, respectively. As seen on the top row images L-R, microscopic analysis showed that the wild-type, Bh Houston-1 exhibits heavy growth, adhesion, and aggregation in comparison to Bh Houston-1 $\triangle b a d A$. The Bh Houston-1 $\triangle b a d A / p N S 2 \mathrm{P}_{\text {Trc }} b a d A$ complement displayed an intermediate level of growth and aggregation. Bh Houston-1 $\triangle b a d A$ demonstrates sparse adhesive and aggregative properties apparent in its reduced micro-colony formation. Using Alcian blue dye dissolved in aldehyde solvents, 


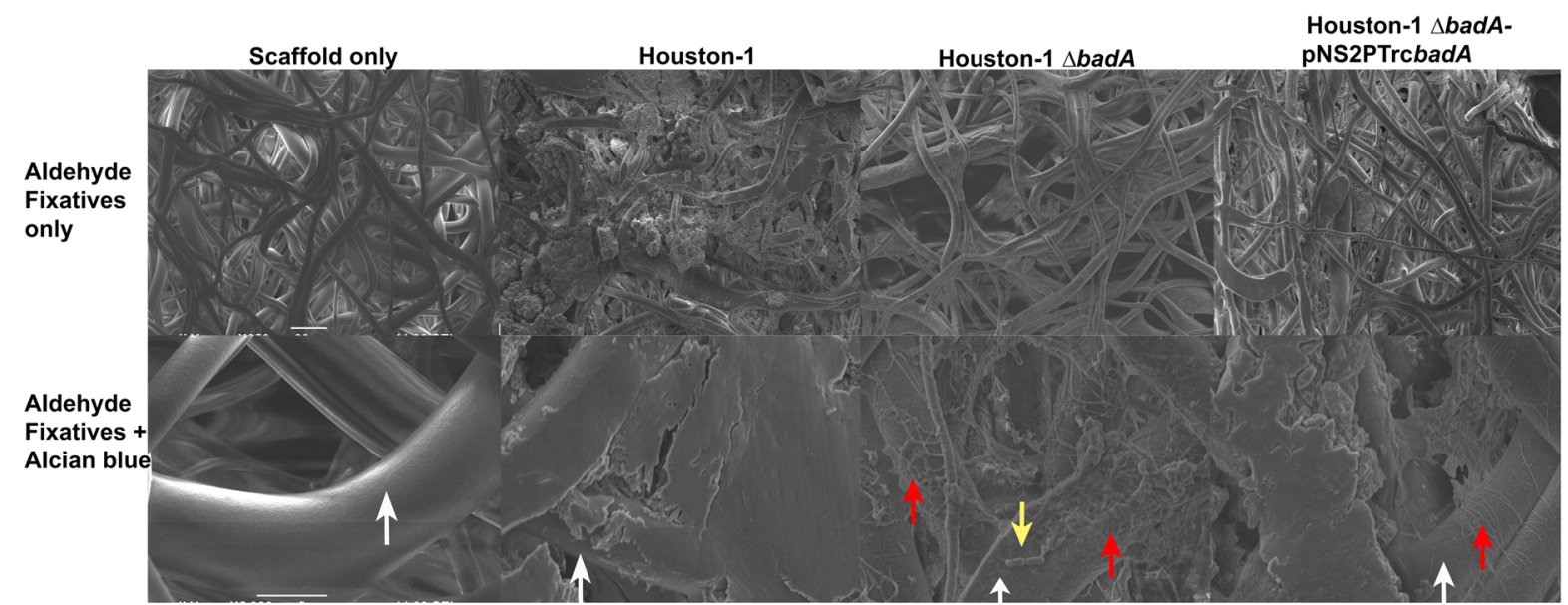

Fig. 3 Scanning electron microscopy images of $\mathrm{Bh}$ biofilms. Biofilms established on a $3 \mathrm{P}$ scaffold after $72 \mathrm{~h}$ incubation at $37^{\circ} \mathrm{C}$ and $5 \% \mathrm{CO}_{2}$. The top row (scale bar- $20 \mu \mathrm{m}$ ) shows bacterial growth, adhesion, and aggregation around the scaffold branches, preserved by the addition of fixatives (aldehydes only). Bottom row (scale bar: $5 \mu \mathrm{m}$ ): EPS was preserved by the addition of cationic dye, Alcian blue. White arrow depicts bare scaffold and yellow arrow depicts single bacteria rods not covered by EPS. Red arrow depicts areas of reduced biofilm

a

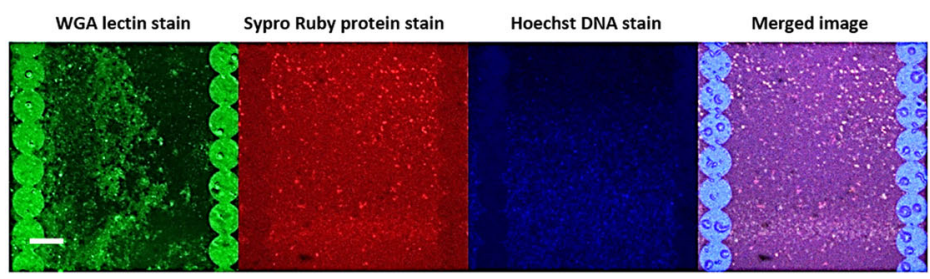

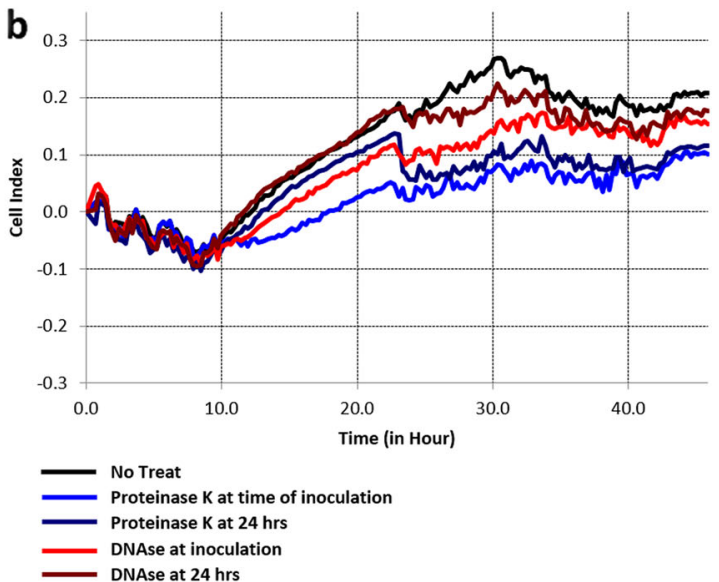

Fig. 4 Imaging the components of a $B h$ biofilm grown for $48 \mathrm{~h}$ using fluorescent-based stains. Graphs show real-time cell monitoring observing the effects of enzyme added either at the time of inoculation or using a 24-hour-old Bh biofilm. a CLSM images of a Bh biofilm with WGA fluorescein (polysaccharides), SYPRO Ruby (protein) and Hoechst (DNA) stains (scale bar, $23 \mu \mathrm{m}$ ). $\mathbf{b}$ Inhibitory effects of proteinase K and DNase on a $B h$ biofilm $(n=6)$

we preserved the bacterial EPS providing a quantitative image of the bacterial biofilm (Fig. 3, bottom row). The bottom images confirm that Bh Houston-1 also produced the most biofilm with a smooth layer covering its dense growth. Although the scaffold is still visible (white arrows), it is mostly covered by the biofilm matrix. In contrast, Bh Houston-1 $\triangle b a d A$ demonstrated a thin layer of biofilm (red arrow) with some bacterial cells bare and unprotected by a matrix (yellow arrow). Despite a complete deletion of the badA gene in $B h$ Houston-1 $\triangle b a d A$, the bacteria still display minimal adhesion with reduced biofilm formation. Finally, Bh Houston-1 $\triangle b a d A / p N S 2 \mathrm{P}_{\text {Trc }}$ badA exhibits an incompletely assembled biofilm showing that complementation with portions of the badA gene can restore limited biofilm formation.

We also investigated the presence of DNA, proteins, and polysaccharides in a $B h$ biofilm using CLSM. An experiment was performed on the e-plates used for the real-time cell adhesion monitoring. The plates were stained with dyes which are capable of binding to polysaccharides (wheat germ agglutinin), protein (sypro ruby), and DNA (DAPI). Figure 4a shows dyes binding to the biofilm components confirming that a Bh Houston-1 biofilm contains polysaccharides, proteins, and DNA.
Proteinase $\mathrm{K}$ and DNase 1 inhibits $B h$ biofilm formation

The ability of two enzymes, - Proteinase K and DNase1-, to inhibit Bh biofilm formation was measured using both a standard biofilm/ crystal violet assay on a 96 well polystyrene plate as well as the $x$ Celligence RTCA monitoring. The cells were treated either at inoculation or $24 \mathrm{~h}$ after inoculation. Real-time monitoring of $B h$ Houston- 1 cells cultured and treated with $10 \mathrm{ug} / \mathrm{ml}$ of proteinase $\mathrm{K}$ resulted in a significant decrease (40\%-66\% inhibition) in biofilm

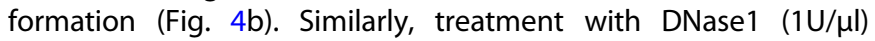
resulted in a slight reduction in $B h$ biofilm (22\%-43\% inhibition). Quantification of $B h$ biofilm by standard biofilm assay and crystal violet staining on a 96 well plate also shows similar levels of biofilm inhibition (see supplementary fig. 3a).

badA expression and Biofilm formation are susceptible to growth temperature and $\mathrm{pH}$

We investigated the response of $B h$ to changes in environmental temperature. At a lower temperature that is consistent with the $C$. felis vector in its environment, the cell index for $B h 48 \mathrm{~h}$ post inoculation was $15 \%$ more than the cell index at $37^{\circ} \mathrm{C}$ temperature which correlates with the cat or human host 
a
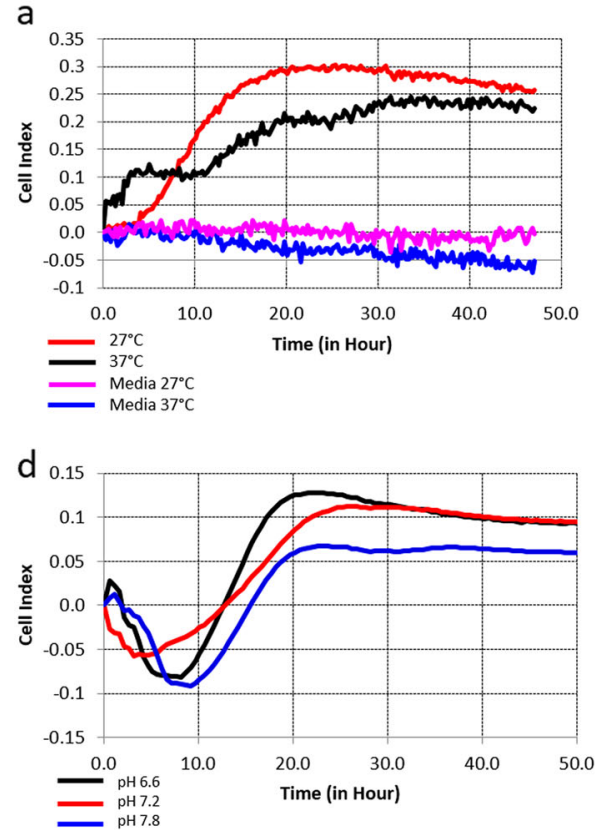

b
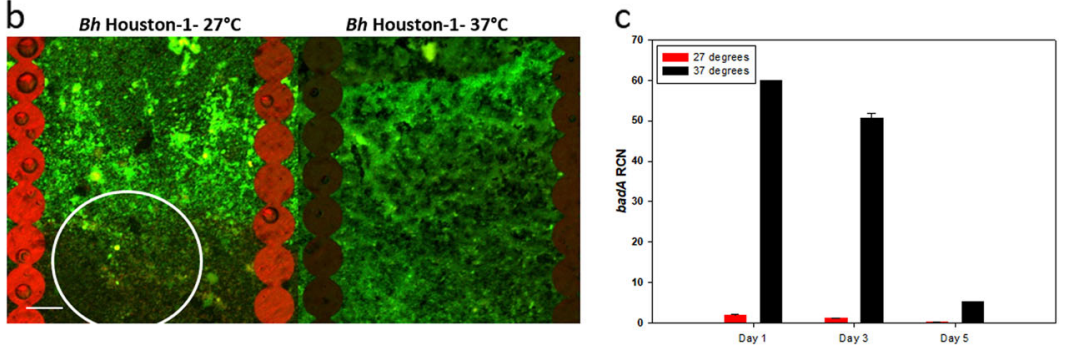

e

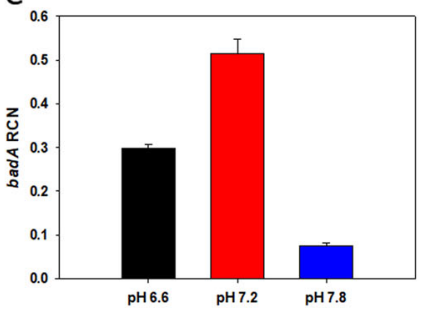

Fig. 5 badA expression and biofilm formation in $B h$ Houston- 1 is susceptible to growth conditions. Biofilm grown for $48 \mathrm{~h}$ and $5 \% \mathrm{CO}_{2}$. a Realtime cell adhesion monitoring at different temperatures $(n=6)$. b CLSM image of $B h$ cells within a biofilm at different temperatures using the STYO9/PI live/dead staining (scale bar, $23 \mu \mathrm{m}$ ). The viability assay was carried out post the experiment depicted in (a). c badA transcript levels from bacteria grown at different temperatures. RNA was extracted on days 1, 3 and 5. d Growth of a $B h$ biofilm at varying pH. e badA gene expression in Bh biofilm grown at varying $\mathrm{pH}$. Error bars represent the standard error of mean. Data set $(n=3)$

(Fig. 5a). We compared the viability of the cells within a biofilm in different temperature using the SYTO9/PI stain. A larger percent of $B h$ cells are viable when grown at $37^{\circ} \mathrm{C}$ compared to cells grown at $27^{\circ} \mathrm{C}$ (Fig. 5b). Cells grown at $27^{\circ} \mathrm{C}$ displayed more red/yellow cells (white circle) indicative of disrupted membranes and reduced viability. badA expression is also increased at $37^{\circ} \mathrm{C}$ supporting the hypothesis that at $37^{\circ} \mathrm{C}, \mathrm{Bh}$ requires BadA to form a biofilm (Fig. 5c).

The effect of $\mathrm{pH}$ on $\mathrm{Bh}$ biofilm was compared using growth media with $\mathrm{pH}$ of $6.6,7.2$, and 7.8. At neutral or slightly acidic $\mathrm{pH}$, $\mathrm{Bh}$ cells form biofilms more efficently in contrast to alkaline $\mathrm{pH}$ (7.8) (Fig. 5d). There is no statistical difference between growth in media with $\mathrm{pH}$ of 6.6 and 7.2, however, badA expression is statistically different at $\mathrm{pH}$ of 7.2 (Fig. 5e). We see that the expression of badA gene is optimal at the inoculation $\mathrm{pH}, 7.2$, at day 1 and gradually decreases as a biofilm is formed (Fig. 5c). Interestingly, the $\mathrm{pH}$ goes up during the initial stages of biofilm formation $(24 \mathrm{~h})$ and then declines at $48 \mathrm{~h}$ for the BadA expressing stains, Bh Houston-1, and Bh Houston-1 $\triangle b a d A / p N S 2 P_{\text {Trc }} b a d A$. However, Bh Houston-1 $\triangle b a d A$ maintains a near neutral pH 7.2 across the same time period (see supplementary fig. $3 \mathrm{~b}$ ).

\section{DISCUSSION}

We investigate the major adhesin, BadA, found on the outer membrane of $B h$ Houston- 1 and its effect on biofilm formation. We also examined the composition of the $B h$ biofilm and expression of badA gene under different growth conditions. BadA is a TAA which has been implicated as one of the major proteins responsible for attachment and aggregation, the first step of biofilm formation in $B h^{22}$ As the expression of BadA is diminished after multiple passages, we routinely used $B h$ Houston- 1 from a frozen stock stored at $-80^{\circ} \mathrm{C}$ and the bacteria are discarded after four passages to prevent loss of adhesin expression. ${ }^{23}$ To determine if $B h$ forms a biofilm, we cultured the bacteria on 96 well polystyrene plates with cellulose membranes at the bottom over the course of $72 \mathrm{~h}$. After observing the presence of biofilms microscopically, we measured and quantified the formation of biofilms in strains with, and without BadA (Fig. 1).

Using Bh Houston-1, Bh Houston-1 $\triangle b a d A$ (a complete in-frame badA deletion mutant) ${ }^{24}$ and $B h$ Houston-1 $\triangle b a d A /$ pNS2P $\mathrm{P}_{\text {Trc }} b a d A$ (a partial complement of badA consisting of the $\mathrm{N}$-terminal head, a truncated neck region with only the terminal neck domain, and the C-terminal membrane anchor) (this study), we investigated the differences in gene expression, biofilm formation and composition. The size of BadA varies between different strains of the $B h$ owing to its stalk region size. ${ }^{23}$ However, regardless of the mass of the individual BadA variant, they still retain the characteristic head-neck-membrane anchor organization of TAAs. Considering the size of BadA ( $328 \mathrm{kDa}$ per monomer), our numerous attempts to make a full-length BadA complement proved unsuccessful, as also reported by others attempting to make such a construct. ${ }^{25}$ Previous reports show that the $\mathrm{N}$-terminal head and the $\mathrm{C}$ terminal anchor are required for adhesion, aggregation, and mediation of a proangiogenic response in the host. ${ }^{14}$ Using the sequence analysis and functions outlined in Kaiser et al., ${ }^{26}$ we amplified sequences coding for the signal sequence for BadA, unassigned domain, YadA-like head repeats and the BadA head (amino acid res. 1-511). The coding region for this 511 amino acid region was fused in-frame to a PCR amplicon coding for the terminal neck sequence and the membrane anchor region (residues 2873-3103) to produce a 741 amino acid protein. The coding regions for this 741 amino acid residue truncated protein was ligated into the $\mathrm{pNS} \mathrm{P}_{\mathrm{Trc}}$ vector and cloned downstream of the promoter, $P_{\text {Trc }}$ (see supplementary fig. $1 \mathrm{~b}$ ). $P_{\text {Trc }}$ is known to promote high levels of transcription from $B h$ plasmids, ${ }^{21}$ hence it was not unexpected that $B h$ Houston-1 $\triangle b a d A / p N S 2 P_{\text {Trc }}$ badA shows high badA transcript levels when compared to the wildtype (see supplementary fig. 1b). While supplementary fig. 2 shows surface localization of the truncated BadA, the levels of BadA protein were not proportionally as high as the corresponding mRNA (see supplementary fig. $1 \mathrm{~b}$ ). This suggests that the truncated protein may be more susceptible to protease degradation or incompletely translocated to the outer membrane 
compared to the native full-length BadA. Previously, we reported that the genome sequence of our badA locus does not bear the base pair deletion reported by Alsmark et al., 8,27 in our isolate, loci $\mathrm{BH} 01510$ and $\mathrm{BH} 01520$ are merged as one open reading frame and surface localized as demonstrated using a BadA antibody specific for the C-terminal part of the BadA head as seen in supplementary fig. 2 .

The microplate assay is one of the most frequently used methods for the measurement of in vitro biofilms. While it is simple and inexpensive, it has been reported to be sensitive to sedimentation, and loosely attached biofilm, and not always reproducible. To avoid these issues, xCelligence's RTCA was used. High cell index levels of Bh Houston-1 and Bh Houston-1 $\triangle b a d A /$ pNS2 $\mathrm{P}_{\text {Trc }}$ badA were expected however the Bh Houston-1 $\triangle b a d A$ numbers was unanticipated (Fig. 2a). Growth rate experiments over $96 \mathrm{~h}$ show that all three strains do not significantly differ (see supplementary fig. 1c), hence the increased cell impedance from the Bh Houston-1 $\Delta b a d A$ mutant was not due to increased growth rate and did not correlate with our previous data showing that the mutant produced less biofilm in comparison to the wild-type. ${ }^{8} \mathrm{At}$ the end of the real-time monitoring, we determined the cell density $\left(\mathrm{OD}_{600}\right)$ in the supernatant of each strain. The $\mathrm{OD}_{600}$ recorded by $B h$ Houston-1 $\triangle b a d A$ was twice as high as $B h$ Houston-1 and $10 \%$ more than Bh Houston-1 $\triangle b a d A /$ pNS2P $\mathrm{P}_{\text {Trc }}$ badA (Fig. 2c), hence the real-time analysis output was either adherent cells not present in a mature biofilm or sediment from planktonic or dead cells. We used a crystal violet stain on the e-plates post-real-time monitoring to demonstrate that $B h$ Houston-1 $\triangle b a d A$ formed less biofilm, $13 \%$ in comparison to $B h$ Houston-1, and $20 \%$ of the biofilm formed by Bh Houston-1 $\triangle b a d A / p N S 2 P_{T r c} b a d A$ (Fig. 2b). Despite the complete in-frame deletion of BadA, Bh Houston-1 $\triangle b a d A$ still forms a biofilm. This can be attributed to the presence of other outer membrane proteins present on the surface of the bacteria such as the outer membrane proteins which bind endothelial cells (EC) and fibronectin ${ }^{28}$ and function as adhesins resulting in a biofilm considerably diminished in biomass when compared to the parental strain.

As a confirmation to the RTCA reading, we observed bacteria cell viability within the biofilm on the e-plate post-real-time monitoring. The viability assay combines the use of SYTO9 and PI for the assessment of cell viability. In Fig. 2d, yellowish fluorescence (white arrows) can be seen indicating partial membrane disruption/incomplete SYTO9 displacement. ${ }^{29}$ Microscopic examination of the biofilm population using CLSM show a profound biofilm surface apparent from the hazy aggregates which give off a green fluorescence in Bh Houston-1. While the majority of the Houston-1 cells indicate an intact membrane confirming cell viability within the biofilm, we do observe dead or compromised cells (white arrow). Bh Houston-1 $\triangle$ badA/ pNS2 $\mathrm{P}_{\text {Trc }}$ badA does not exhibit as much biofilm as the wild-type strain but it does display adhesion and aggregation properties with cell viability comparable to the Bh Houston-1. Although the RTCA real-time monitoring records the most impedance from the $B h$ Houston-1 $\triangle b a d A$, the viability assay shows that a majority of the bacterial population fluoresces red (white circle), which suggests that a significant amount of the cells recorded by the gold electrodes are dead cells within the biofilm.

At high cell density, bacteria communicate using chemical signal molecules. This process is referred to as quorum sensing and a crucial aspect of biofilm formation as it prevents overpopulation through nutrient conservation and regulating gene expression. It is also a signal to initiate biofilm formation. Hence we hypothesize that in the absence of tight adherence by the $B h$ Houston-1 $\triangle b a d A$, quorum sensing is not initiated prompting the populous growth of $B h$ Houston-1 $\triangle b a d A$. Overpopulation will lead to nutrient exhaustion and eventually cell death as seen in Fig. $2 \mathrm{~d}$ (white circle).
Using SEM, we visualized the three-dimensional structures of the biofilms with a scaffold and using staining methods previously described in Behnke $O$ and Zelander T (1970). ${ }^{30}$ Bacterial cells cultured on the scaffold formed aggregates around the scaffold, similar to vegetations seen in in vivo infective endocarditis. The biofilm formed also maintained structural integrity through sample processing. In Fig. 3, the top row shows a 3-dimensional image of the scaffold followed by images of bacteria grown on a scaffold. Bh Houston-1 and Bh Houston-1 $\triangle b a d A / p N S 2 P_{\text {Trc }} b a d A$ both show bacteria aggregates with the $B h$ Houston-1 exhibiting heavy growth enveloping the scaffold surface. Growth and adhesion to scaffold branches by Bh Houston-1 $\triangle$ badA were reduced compared to BadA expressing strains. Alcian blue is a cationic dye known to stain and preserve the structure of polysaccharides by binding carboxyl or sulfate groups present in glycosaminoglycan/mucopolysaccharides to form an insoluble complex. ${ }^{30}$ The biofilm formed was vastly different between strains. Bh Houston- 1 shows a smooth solid mass of biofilm covering the scaffold (white arrow) while Bh Houston-1 $\triangle$ badA/ pNS2P $\mathrm{P}_{\text {Trc }}$ badA shows less biofilm with more visible scaffolds (white arrow). In contrast, Bh Houston-1 $\triangle b a d A$ mirrors the sparsity of its aggregation in its biofilm production. The $\triangle b a d A$ strain shows light biofilm production and obvious single rod-shaped cells (yellow arrow) on the surface of the scaffold.

Using CLSM, we identified the major constituents of a biofilm. WGA fluorescein is an extensively used lectin which binds $\mathrm{N}$ acetylglucosamine and sialic acid residues emitting a green fluorescence. Hoechst is a nucleic acid stain which emits blue fluorescence when bound to A-T regions of DNA and Sypro-ruby is a ruthenium-based fluorescent dye which emits a red fluorescence when it interacts with basic amino acids like lysine, and histidine. ${ }^{31}$ All three stains demonstrate that the $B h$ biofilm is made up of eDNA, protein, and polysaccharides (Fig. 4a). As e-DNA and protein would be sensitive to DNase and proteinase $K$ cleavage, we treated cells either during inoculation, or $24 \mathrm{~h}$ post inoculation. Treatment with both proteinase $\mathrm{K}$ and DNase markedly reduced the biofilm (Fig. 4b, see supplementary fig. 3a). Both treatments at the time of inoculation did not completely inhibit biofilm formation but it reduced its formation to less than $50 \%$. Maturing biofilms $(24 \mathrm{~h})$ were more resistant to the application of the proteolytic enzyme. This was expected as biofilms are more resistant to stressors. It was also expected that we would not observe a complete dispersal because a biofilm matrix involves protein interactions with exopolysaccharides and nucleic acid components. Hence we predicted that while proteinase $\mathrm{K}$ will induce an increased inhibitory effect, it would not result in the complete dispersal of the biofilm. The sensitivity of the biofilm to both enzymes confirms the presence of proteinaceous components and extracellular DNA.

Finally, we examined the effects of environmental conditions on a Bh Houston-1 biofilm formation. One of the major differences between the arthropod vector of Bh, C. felis, and the mammalian host is temperature. Bh must adapt to the lower temperature while inhabiting the $C$. felis vector and rapidly adjust to the higher temperature of the vertebrate host such as cats and humans. To simulate the temperature of fleas in the environment, $B h$ was grown at $27^{\circ} \mathrm{C}$, a representative temperature reported to model an environment for adult flea activity. ${ }^{32,33}$ It has been speculated that bacterial persistence and colonization in the flea gut is temperature dependent. ${ }^{33}$ It has also been shown that Yersinia pestis also transmitted through the $C$. felis vector is able to form a biofilm in the flea gut and feces. ${ }^{34}$ We examined the effect of temperature on badA/BadA expression and biofilm formation in $B h$. While there is no statistical difference between cell adhesion and biofilm formation under different temperatures, $B h$ grown at $27^{\circ} \mathrm{C}$ rapidly forms a biofilm in comparison to $B h$ grown at $37^{\circ} \mathrm{C}$ (Fig. 5a). Microscopically examining the adherent cells shows that under temperature consistent with the mammalian host, $B h$ cells 
within the biofilm are more viable when compared to lower temperatures growth (Fig. 5b). Perhaps, bacterial persistence at the $27^{\circ} \mathrm{C}$ temperature is reduced as observed by Schotthoefer et al..$^{33}$ In that study, fleas which were held at $27^{\circ} \mathrm{C}$ transmitted $Y$. pestis but lower flea survival rate and bacterial load were noted as infection progressed. To confirm if bacteria are unable to persist at $27^{\circ} \mathrm{C}$ because of differential gene expression, we looked at the expression of badA at the lower temperature. Previous studies with other bacteria have shown that expression of some surface proteins are dependent on temperature with lower temperatures resulting in less adhesin expression. ${ }^{35}$ badA was not efficiently expressed at $27^{\circ} \mathrm{C}$ when compared to the high expression rate at $37^{\circ} \mathrm{C}$ (Fig. $5 \mathrm{C}$ ), leading us to speculate that perhaps the reduced rate of badA expression and adhesion is correlated to the low cell viability observed in Fig. 5b. Other outer membrane proteins like the filamentous hemagglutinin (Fha) may compensate for the diminished role of BadA at $27^{\circ} \mathrm{C}$. Bh is known to harbor eight varying length gene copies of filamentous hemagglutinin homologs. ${ }^{27}$ FhaC also found in $B h$ is known to be involved in mediating transport of filamentous hemagglutinin and is controlled by Bat $R$, part of a two-component regulatory system. ${ }^{36}$ BatR/S is known to be activated by $\mathrm{pH}$ which also differs between arthropods and mammals during $B h$ adaptation. ${ }^{36}$ In conditions consistent with mammals, Bh transcribes badA efficiently within the first few days of growth when the adhesin is needed for optimal aggregation and adhesion. Then badA transcription slows down once the biofilm is assembled (Fig. 5c). At this stage of biofilm development, polysaccharides are produced for the assembly of the extracellular matrix. Whereas less BadA and other surface adhesins will be needed to aggregate cells within the biofilm (cohesive force). Differential gene expression has been observed within other bacterial biofilms where the production of surface appendages like flagella has been reported to be reduced in sessile species with an increase in surface proteins used for transportation and excretion of extracellular products. ${ }^{37}$

Data from Fig. $5 \mathrm{~d}$ shows that a neutral $\mathrm{pH}$ favors bacterial growth, and badA transcription (Fig. 5e) as was described previously. ${ }^{38}$ Excretion of polysaccharides, one of the components of biofilm EPS, has been shown to be sensitive to $\mathrm{pH}^{39}$ An alkaline environment favors biofilm development as seen in supplementary fig. 3b. The $\mathrm{pH}$ of growth media when a biofilm is being formed is slightly alkaline ( $\mathrm{pH} 7.5)$. After the biofilm is formed, we observed a decline in media $\mathrm{pH}$ for BadA expressing cells possibly due to the metabolism of amino acids in Schneider's media. It is interesting to note that $B h$ Houston-1 $\triangle b a d A$ maintains an alkaline $\mathrm{pH}$ throughout the entire growth period (see supplementary fig. $3 b)$. Bh has been shown to catabolize amino acids through the TCA cycle releasing $\mathrm{CO}_{2}$ which will contribute to an acidic $\mathrm{pH}$. The TCA cycle releases carbon used to generate ATP and provide the energy needed for a variety of downstream effects like activation of response regulators in a two-component system. It is possible that since planktonic cells do not need to expend as much energy making a biofilm, the TCA cycle may be under-utilized. In Pseudomonas fluorescens, planktonic metabolism was characterized by a change in metabolome products. The biofilm bacteria instead exhibited exopolysaccharide metabolism. ${ }^{40}$ In Staphylococcus aureus, the level of succinate produced was significantly reduced but there was an upregulation of succinate dehydrogenase activity in biofilm bacteria in comparison to the planktonic bacteria. ${ }^{41}$

EC have been previously proposed as the primary niche for $B h$ but it has also been reported that $B h$ can survive in other cells types. ${ }^{42,43}$ Regardless of the cells that have been proposed as a primary niche for Bartonella species, intracellular bacteria are not often observed in specimens collected directly from patients infected with $\mathrm{Bh}^{44}$ An immuno-compromised mouse model showed aggregates of Bartonella taylorii within a collagen matrix. $^{45}$ Full-length BadA has also been shown to bind erythrocytes, EC, fibronectin and collagen. ${ }^{26,46}$ From these reports and our data, we can hypothesize that since BadA is required for optimal biofilm formation, it also plays a major role in $B h$ persistence and infection. Hence, it is likely that $B h$ uses BadA as an adhesin to attach itself to a wide range of cells and extracellular matrix proteins. There, the bacteria forms a biofilm comprised of polysaccharides, protein, and e-DNA that help the bacteria prevent phagocytosis and contributes to its persistence. We hypothesize that $B h$ cells are disseminated from the biofilm to circulate in the bloodstream to continue and spread infection, explaining the enigma of persistent or relapsing bacteremia in patients infected with $B h$. Thus, we further propose that the ability to form biofilms may be more important in bacterial persistence and the establishment of a primary niche than an intracellular growth location. BadA plays a critical role in this process as we have shown in this report and as observed in patients with infective endocarditis caused by $B h^{8}$

Finally, we present evidence that warmer temperatures and neutral $\mathrm{pH}$ consistent with the mammalian host are optimal for growth, adhesion, and badA expression. Since badA is not expressed efficiently at lower temperatures more consistent with adult fleas in the environment, we propose that other outer membrane proteins may be expressed in vivo in the flea. Future directions will focus on gene expression in the flea vector and flea feces. We hypothesize that BadA is also used by the bacterium to adhere and aggregate in the fecal matter before the bacteria secretes the EPS which supports its ability to persist in the flea feces. This is the first report demonstrating the importance of TAA/ BadA during formation of a $B h$ biofilm.

\section{MATERIALS AND METHODS}

Bacteria strains and growth condition

E.coli strains DH5a (Invitrogen), Bh Houston- $1,{ }^{47}$ Bh Houston- $1 \Delta b a d A^{24}$ and $B h$ Houston-1 $\triangle b a d A / p N S 2 P_{T r c} b a d A$ (this study) were all used for this study (Table 1). E.coli $\mathrm{DH} 5$ a was grown at $37^{\circ} \mathrm{C}$ on either $\mathrm{LB}$ agar or liquid $\mathrm{LB}$ broth. The Houston-1 strain of $B h$ used for this study was isolated from an HIV patient. ${ }^{47} B h$ was grown on heart infusion agar supplemented with $1 \%$ bovine hemoglobin or liquid Schneiders media (Sigma Aldrich, S9895) supplemented with $10 \%$ fetal bovine serum for 3 days as described by Riess et al. ${ }^{48}$ Growth conditions were kept at $5 \% \mathrm{CO}_{2}$ at $37^{\circ} \mathrm{C}$. Bh Houston$1 \triangle b a d A$, a non-polar in-frame deletion mutant of badA has been described by Lima et al., 2014. ${ }^{24}$ Bh Houston-1 $\triangle b a d A / p N S 2 P_{\text {Trc }}$ badA construction is described as below. Bh Houston-1 $\triangle b a d A / p N S 2 \mathrm{P}_{\mathrm{Trc}}$ badA was grown on agar supplemented with kanamycin $(50 \mu \mathrm{g} / \mathrm{ml})$.

\section{Bh Houston-1 $\Delta b a d A / p N S 2 T r c b a d A$ construction}

As previously published by Schmidgen et al., ${ }^{25}$ we were also unable to attain a full-length BadA construct after three attempts, so we constructed a BadA partial complement. Based on the work of Kaiser et al., ${ }^{26}$ PCR primers were designed to amplify the full-length head of BadA, the last neck region before the membrane anchor domain, and the membrane anchor. Primer pair badAF1 and badAR1 was used to amplify a $1533 \mathrm{bp}$ fragment which codes for the BadA signal, unassigned domain, YadA-like head repeats, BadA head, and the BadA head C-terminal part (Amino acids res. 1-511). This was ligated in-frame to 1003 bp fragment amplified using primer pair badAF2 and badAR2 coding for the last neck sequence and membrane anchor (amino acid res. 2873-3103) (see supplementary fig. 1a) (Nucleotide sequence sourced from NCBI Reference Sequence: NC_005956.1). The resulting amplicons were ligated using the BamHI and $\mathrm{Xbal}$ restriction sites of the $\mathrm{pNS}_{2} \mathrm{P}_{\mathrm{Trc}}$ plasmid. The plasmid was transformed into E.coli DH5a (Invitrogen, Cat no; 18-258-012). Positive colonies were confirmed by PCR and Sanger sequencing. The resulting plasmid was extracted (Zymopure plasmid midiprep, 50-136-6986). $2 \mathrm{ng}$ of plasmid was electroporated into Bh Houston-1 $\triangle b a d A$ as described by Resto-Ruiz et al. $2000{ }^{49}$ The resulting clone for Bh Houston-1 $\Delta$ badA/ pNS2P $\mathrm{P}_{\mathrm{Tr}}$ badA was selected using kanamycin $(50 \mu \mathrm{g} / \mathrm{ml})$. 


\section{Gene expression in $B h$ biofilm}

To examine the expression of badA in Bh biofilm, $B h$ was cultured in Schneider's liquid media at $37^{\circ} \mathrm{C}, 5 \% \mathrm{CO}_{2}$ for 1,3 , or 5 days on a 6 well polystyrene plate (Corning \#3506). The supernatant was carefully aspirated to prevent biofilm disruption. The biofilm was gently washed twice with PBS and the RNA was extracted by directly adding Trizol reagent (Life Technologies, \#15-596-026) to the plate. $10 \mu \mathrm{g}$ of the resulting RNA was treated with Turbo DNase (Thermo Fisher Scientific, AM1907), and $1 \mu \mathrm{g}$ reverse transcribed to CDNA using the iScript CDNA synthesis kit (BioRad, 1708891). qRT-PCR was performed in a total volume of $25 \mu \mathrm{l}$ which consist of $12.5 \mu \mathrm{l}$ of the 2X Maxima SYBR Green/Fluorescein qPCR kit (Thermo Fisher Scientific, K0241), $300 \mathrm{nmol}$ of the forward and reverse badA primers (Screen $1 \mathrm{~F}$ and $1 \mathrm{R}$ ) (Table 1), and $2 \mu \mathrm{l} \mathrm{cDNA}$. The $50 \mathrm{~S}$ ribosomal protein L4 (rplD), was used as the reference gene for normalization. The reaction conditions were as follows: a single cycle of $95^{\circ} \mathrm{C}$ for $3 \mathrm{mins}, 40$ cycles of $95^{\circ} \mathrm{C}$ for $10 \mathrm{~s}$, and $60^{\circ} \mathrm{C}$ for $30 \mathrm{~s}$, followed by $95^{\circ} \mathrm{C}$ for $45 \mathrm{~s}$ and $55^{\circ} \mathrm{C}$ for $1 \mathrm{~min}$. Melt curve analysis was used to confirm that primer dimers were not generated. The comparative CT method was used to analyze data. ${ }^{50}$

\section{Monitoring cell adherence or impedance in real-time}

The $x$ CELLigence ${ }^{\circledR}$ System real-time cell analyzer (RTCA) (ACEA Bioscience Inc.) was used to measure and monitor cell adherence. This system measures cell adherence by recording the electrical impedance signal from adherent cells on the bottom of specialized 96 well e-plates (ACEA, Biosciences Inc.) with gold microelectrodes. Maximum $\mathrm{Cl}$ is achieved when the surface of the microelectrode is covered by cells giving a constant $\mathrm{Cl}$. This saturated $\mathrm{Cl}$ remains constant during biofilm formation but decreases during detachment. ${ }^{20}$ Cells were seeded onto the plates using the same protocol as the standard biofilm assay described below and real-time measurement occurs every 15 mins. The growth conditions were kept at $37{ }^{\circ} \mathrm{C}$ and $5 \% \mathrm{CO}_{2}$. A crystal violet stain was used at the end of the growth to determine the amount of biomass in each well. Post incubation, wells were washed with sterile water to remove planktonic cells and stained with $0.1 \%$ crystal violet solution for 15 mins. Wells were washed again and decolorized using $30 \%$ acetic acid and the absorbance at $550 \mathrm{~nm}$ was measured. Biofilm conditions under different $\mathrm{pH}$, temperature, and treatments (proteinase $\mathrm{K}, 10 \mu \mathrm{g} / \mathrm{ml}$ and $1 \mathrm{U} / \mu \mathrm{l}$ DNase1) were carried out using the same protocol.

\section{Biofilm assay}

Biofilm formation was monitored using 96 well polystyrene plates (Corning \#3585)and crystal violet staining (CV) as described by O'Toole et al. ${ }^{51}$ In all, $10^{6}$ bacteria cells in a $200 \mu$ volume were grown for 1 and 3 days at $37^{\circ} \mathrm{C}$ and $5 \% \mathrm{CO}_{2}$. Cells were washed with water to remove unbound cells and stained with $0.1 \%$ crystal violet solution. The stained biofilm was washed with water, air dried and extracted using 30\% acetic acid. Bound cells are quantified at an optical density of $550 \mathrm{~nm}$ (OD550) (Biotek, Winooski, VT).

For some experiments, $10 \mu \mathrm{g} / \mathrm{ml}$ of proteinase $\mathrm{K}$ or $1 \mathrm{U} / \mu \mathrm{l}$ of DNase was added to each well at the time of inoculation and $24 \mathrm{~h}$ after inoculation.

\section{BadA synthesis in $B h$}

To determine if the transcription rate of the badA gene in Bh Houston-1 $\triangle b a d A / p N S 2 P_{\text {Trc }}$ badA corresponds with BadA protein expression, we performed CLSM.

Bh Houston-1, Bh Houston-1 $\triangle b a d A$, and Bh Houston-1 $\triangle b a d A$ / pNS2 $\mathrm{P}_{\text {Trc }}$ badA were all grown overnight on a six chamber slide. The supernatant is carefully aspirated and cells were washed using PBS. Cells were fixed with $4 \%$ paraformaldehyde for 20 mins at room temperature. Post fixation, cells were washed again and blocked with $5 \%$ non-fat milk. Anti BadA antibody diluted 1:200 in PBS $+5 \%$ skim milk was added and the slides and incubated overnight at $4{ }^{\circ} \mathrm{C}$. Slides were washed four times in PBS $+0.05 \%$ Tween 20 and incubated in goat anti-rabbit conjugated with Alexa 488 fluorescein for $1 \mathrm{~h}$ at room temperature. After secondary antibody incubation, slides are washed, mounted, air dried and imaged.

\section{Immunofluorescence assay}

For CLSM imaging to confirm components of a Bh biofilm, the 96 well eplates used for real-time monitoring were gently washed to prevent biofilm disruption. Molecular probes: Film Tracer biofilm viability kit (Invitrogen L10316), Hoechst stain (Thermofisher \#33342), Sypro ruby biofilm matrix stain (Invitrogen, \#F10318), and the Wheat germ agglutinin fluorescein conjugate (Invitrogen W834) were used to stain wells according to manufacturer's protocols. Stains were left on for 15-30 mins and washed with sterile water. Wells were imaged immediately after washing with sterile water. Samples were examined using an Olympus Fluoview FV1000 microscope.

\section{The growth of Bh on the 3-dimensional scaffold}

To visualize and quantitate the amount of biofilm formed by $B h$, bacteria were inoculated onto either a nitrocellulose membrane (Fig. 1) or the 3dimensional nanofibrous scaffold (Fig. 3). The 3-dimensional nanofibrous scaffold was produced by electrospinning a mixture of poly (lactic-coglycolic acid) (PLGA) and a block copolymer of polylactic acid (PLA) and mono-methoxypolyethylene glycol (mPEG) designated as $3 P .{ }^{19}$ To sterilize, the scaffold/membrane was immersed in absolute ethanol for 15 secs and washed with PBS. The scaffold/membrane was transferred into 96 well plates containing $50 \mu \mathrm{l}$ of PBS and placed under UV wavelength light for 45 mins. The well was washed with $100 \mu \mathrm{l}$ of media, inoculated with $150 \mu \mathrm{l}$ of the bacterial cells $\left(10^{6}\right.$ at $\left.\mathrm{OD}_{600}\right)$ and grown at $37^{\circ} \mathrm{C}, 5 \% \mathrm{CO}_{2}$ for $12 \mathrm{~h}$. $50 \mu \mathrm{l}$ of media was added to each well and grown for $8-72 \mathrm{~h}$. The scaffold/ membrane was fixed overnight in a mixture of $2 \%$ paraformaldehyde and $2 \%$ glutaraldehyde in $0.2 \mathrm{M}$ sodium cacodylate buffer, $\mathrm{pH} 7.2$ with or without $0.15 \%$ alcian blue. Samples were washed $2 x$ in $0.2 \mathrm{M}$ sodium cacodylate and post-fixed for 30 mins in $1 \%$ OsO4. The dehydration step occurred with ascending alcohol order $35 \%-5 \mathrm{~min}, 50 \%-5 \mathrm{~min}$, 75\%-5 mins, $90 \%-5$ mins, $100 \%-10$ mins $2 \times, 50 \%$ hexamethyldisilazane (HMDS) $+50 \%$ of absolute EtOH- 10 mins, Pure HMDS -10 mins. Samples were air dried overnight, mounted on adhesive carbon film and coated for 30 secs with $\mathrm{Au} / \mathrm{Pd}(60 ; 40)$ at $16.40 \mathrm{~g} / \mathrm{cm}$ and $25 \mathrm{~mA}$. Joel JSM6490LV scanning electron microscope operated at $4 \mathrm{Kv}$ was used to image the scaffolds and secondary images collected as TIFF/JPEG.

\section{Statistical analysis}

All cell index experiments were conducted as independent samples of six and mean values compared within and between groups using the student's $t$-tests.

All RT-PCR experiments were conducted as independent triplicates and mean values compared between groups using the student's t-tests. SigmaPlot software (Systat Software, San Jose, CA) was used for statistical analysis. Differences were statistically different for a $P$-value $<0.05$.

\section{Reporting Summary}

Further information on experimental design is available in the Nature Research Reporting Summary linked to this article.

\section{DATA AVAILABILITY}

The authors declare that [the/all other] data supporting the findings of this study are available within the paper [and its supplementary information files]. Data generated are deposited in figshare. (Unique identifier; 10.6084/m9.figshare.7621439)

\section{ACKNOWLEDGEMENTS}

The rabbit polyvalent antibody to the BadA head region used to determine BadA protein expression was a generous gift from Dr. Volkhard Kempf. Special thanks to Dr. Jake Cha and Amanda Garces at the USF Lisa Muma Weitz Laboratory for Advanced Microscopy \& Cell Imaging for help with electron and confocal microscopy. Special thanks to Brandon Lamarche from Acea Bioscience for xCelligence RTCA data analysis and manuscript review.

\section{AUTHOR CONTRIBUTIONS}

B.A. and U.O. conceived the experimental idea, verified the protocol, planned the experiments and wrote the manuscript. U.O. planned and performed the experiments and data analysis. B.A. supervised the findings of this work. S.M. and R.G. developed and supplied the 3-dimensional scaffold used for the experiments.

\section{ADDITIONAL INFORMATION}

Supplementary information accompanies the paper on the npj Biofilms and Microbiomes website (https://doi.org/10.1038/s41522-019-0083-8).

Competing interests: The authors declare no competing interests. 
Publisher's note: Springer Nature remains neutral with regard to jurisdictional claims in published maps and institutional affiliations.

\section{REFERENCES}

1. Muller, N. F. et al. Trimeric autotransporter adhesin-dependent adherence of Bartonella henselae, Bartonella quintana, and Yersinia enterocolitica to matrix components and endothelial cells under static and dynamic flow conditions. Infect. Immun. 79, 2544-2553 (2011).

2. Hoiczyk, E., Roggenkamp, A., Reichenbecher, M., Lupas, A. \& Heesemann, J. Structure and sequence analysis of Yersinia YadA and Moraxella UspAs reveal a novel class of adhesins. EMBO J. 19, 5989-5999 (2000).

3. Wells, T. J., Tree, J. J., Ulett, G. C. \& Schembri, M. A. Autotransporter proteins: nove targets at the bacterial cell surface. FEMS Microbiol Lett. 274, 163-172 (2007).

4. Wang, Y.-P. et al. The haemagglutinin of Avibacterium paragallinarum is a trimeric autotransporter adhesin that confers haemagglutination, cell adherence and biofilm formation activities. Vet. Microbiol. 174, 474-482 (2014).

5. Szczesny, P. et al. Structure of the Head of the Bartonella Adhesin BadA. PLoS Pathog. 4, e1000119 (2008)

6. Anderson, B. E. \& Neuman, M. A. Bartonella spp. as emerging human pathogens. Clin. Microbiol Rev. 10, 203-219 (1997).

7. Chomel, B. B. et al. Experimental transmission of Bartonella henselae by the cat flea. J. Clin. Microbiol. 34, 1952-1956 (1996).

8. Okaro, U., Addisu, A., Casanas, B. \& Anderson, B. Bartonella species, an emerging cause of blood-culture-negative endocarditis. Clin. Microbiol. Rev 30, 709-746 (2017).

9. Debre, R. Cat scratch disease. Mars Med. 87, 375-378 (1950).

10. Jackson, L. A., Perkins, B. A. \& Wenger, J. D. Cat scratch disease in the United States: an analysis of three national databases. Am. J. Public Health 83, 1707-1711 (1993).

11. Brouqui, P. \& Raoult, D. Endocarditis due to rare and fastidious bacteria. Clin. Microbiol. Rev. 14, 177-207 (2001).

12. Schmid, M. C. et al. The VirB type IV secretion system of Bartonella henselae mediates invasion, proinflammatory activation and antiapoptotic protection of endothelial cells. Mol. Microbiol. 52, 81-92 (2004).

13. Kempf, V. A. et al. Evidence of a leading role for VEGF in Bartonella henselaeinduced endothelial cell proliferations. Cell. Microbiology 3, 623-632 (2001).

14. Riess, T. et al. Bartonella adhesin a mediates a proangiogenic host cell response. J. Exp. Med. 200, 1267-1278 (2004).

15. Tu, N. et al. A family of genus-specific RNAs in tandem with DNA-binding proteins control expression of the badA major virulence factor gene in Bartonella henselae. MicrobiologyOpen 6, e00420 (2016).

16. Bouhsira, E. et al. Assessment of persistence of Bartonella henselae in Ctenocephalides felis. Appl. Environ. Microbiol. 79, 7439-7444 (2013).

17. Chomel, B. B. et al. Ecological fitness and strategies of adaptation of Bartonella species to their hosts and vectors. Vet. Res. 40, 29 (2009).

18. Bjarnsholt, T. The role of bacterial biofilms in chronic infections. J. Pathol., Microbiol. Immunol. 121(s136), 1-58 (2013).

19. Girard, Y. K. et al. A 3D fibrous scaffold inducing tumoroids: a platform for anticancer drug development. PLOS ONE 8, e75345 (2013).

20. Gutiérrez, D. et al. Monitoring in real time the formation and removal of biofilms from clinical related pathogens using an impedance-based technology. PLOS ONE 11, e0163966 (2016).

21. Gillaspie, D. et al. Plasmid-based system for high-level gene expression and antisense gene knockdown in Bartonella henselae. Applied. Environ. Microbiol. 75, 5434-5436 (2009).

22. O'Rourke, F., Schmidgen, T., Kaiser, P. O., Linke, D. \& Kempf, V. A. Adhesins of Bartonella spp. Adv. Exp. Med. Biol. 715, 51-70 (2011).

23. Riess, T., Raddatz, G., Linke, D., Schafer, A. \& Kempf, V. A. Analysis of Bartonella adhesin $A$ expression reveals differences between various $B$. henselae strains. Infect. Immun. 75, 35-43 (2005).

24. Lima, A., Cha, B. J., Amin, J., Smith, L. K. \& Anderson, B. Zebrafish embryo model of Bartonella henselae infection. Zebrafish 11, 434-446 (2014).

25. Schmidgen, T. et al. Heterologous expression of Bartonella adhesin A in Escher ichia coli by exchange of trimeric autotransporter adhesin domains results in enhanced adhesion properties and a pathogenic phenotype. J. Bacteriol. 196, 2155-2165 (2014).

26. Kaiser, P. O. et al. The head of Bartonella adhesin A is crucial for host cell interaction of Bartonella henselae. Cell Microbiology 10, 2223-2234 (2008).

27. Alsmark, C. M. et al. The louse-borne human pathogen Bartonella quintana is a genomic derivative of the zoonotic agent Bartonella henselae. Proc. Natl Acad. Sci. USA. 101, 9716-9721 (2004).

28. Burgess, A. W. \& Anderson, B. E. Outer membrane proteins of Bartonella henselae and their interaction with human endothelial cells. Microb. Pathog. 25, 157-164 (1998).
29. Stiefel, P., Schmidt-Emrich, Sabrina, Maniura-Weber, Katharina \& Ren, Qun Critical aspects of using bacterial cell viability assays with the fluorophores SYTO9 and propidium iodide. BMC Microbiol. 15, 36 (2015).

30. Behnke, O. \& Zelander, T. Preservation of intercellular substances by the cationic dye alcian blue in preparative procedures for electron microscopy. J. Ultrastruct. Res. 31, 424-428 (1970).

31. Simpson, R. J. Fluorescent staining of proteins with SYPRO Ruby. CSH Protoc. (5). https://doi.org/10.1101/pdb.prot4567, (2006).

32. de Silva, A. M. \& Fikrig, E. Arthropod- and host-specific gene expression by Borrelia burgdorferi. J. Clin. Investig. 99, 377-379 (1997).

33. Schotthoefer, A. M. et al. Effects of temperature on the transmission of Yersinia Pestis by the flea, Xenopsylla Cheopis, in the late phase period. Parasites \& Vectors 4, 191-191 (2011).

34. Tam, C. et al. YfbA, a Yersinia pestis Regulator Required for Colonization and Biofilm Formation in the Gut of Cat Fleas. J. Bacteriol. 196, 1165-1173 (2004).

35. Klemm, P. Fimbriae: adhesion, genetics, biogenesis, and vaccines, (ed. Klemm P.) Boca Raton, Fla: CRC Press, Inc (1994).

36. Quebatte, M. et al. The BatR/BatS two-component regulatory system controls the adaptive response of Bartonella henselae during human endothelial cell infection. J. Bacteriol. 192, 3352-3367 (2010).

37. Whiteley, M. et al. Gene expression in Pseudomonas aeruginosa biofilms. Nature 413, 860-864 (2001)

38. Chenoweth, M. R. et al. Growth Characteristics of Bartonella henselae in a nove liquid medium: primary isolation, growth-phase-dependent phage induction, and metabolic studies. Appl. Environ. Microbiol. 70, 656-663 (2004).

39. Oliveira, R., Melo, L., Oliveira, A. \& Salgueiro, R. Polysaccharide production and biofilm formation by Pseudomonas fluorescen: effects of $\mathrm{pH}$ and surface material. Colloids Surf. B: Biointerfaces 2, 41-46 (1994).

40. Booth, S. C. et al. Differences in Metabolism between the Biofilm and Planktonic Response to Metal Stress. J. Proteome Res. 10, 3190-3199 (2011).

41. Junka, A. F. et al. Differences in metabolic profiles of planktonic and biofilm cells in Staphylococcus aureus - (1)H Nuclear Magnetic Resonance search for candidate biomarkers. Acta Biochim. Pol. 60, 701-706 (2013).

42. Mandle, T. et al. Infection of human CD34+ progenitor cells with Bartonella henselae results in intraerythrocytic presence of $B$. henselae. Blood 106 1215-1222 (2005).

43. Dehio, C. Bartonella-host-cell interactions and vascular tumour formation. Nat. Rev. Microbiol. 3, 621-631 (2005).

44. Perkocha, L. A. et al. Clinical and pathological features of bacillary peliosis hepatis in association with human immunodeficiency virus infection. New Engl. J. Med. 323, 1581-1586 (1990).

45. Chiaraviglio, L., Duong, S., Brown, D. A., Birtles, R. J. \& Kirby, J. E. An immunocompromised murine model of chronic Bartonella infection. Am. J. Pathol. 176 2753-2763 (2010).

46. Kempf, V. A. et al. Interaction of Bartonella henselae with endothelial cells results in rapid bacterial rRNA synthesis and replication. Cell Microbiol. 2, 431-441 (2000).

47. Regnery, R. L. et al. Characterization of a novel Rochalimaea species, $R$. henselae $s p$. nov., isolated from blood of a febrile, human immunodeficiency virus-positive patient. J. Clin. Microbiol. 30, 265-274 (1992).

48. Riess, T. et al. Analysis of a novel insect cell culture medium-based growth medium for Bartonella species. Applied. Environ. Microbiol. 74, 5224-5227 (2008).

49. Resto-Ruiz, S. I., Sweger, D., Widen, R. H., Valkov, N. \& Anderson, B. E. Transcriptional activation of the htrA (High-temperature requirement $A$ ) gene from Bartonella henselae. Infect. Immun. 68, 5970-5978 (2000).

50. Schmittgen, T. D. \& Livak, K. J. Analyzing real-time PCR data by the comparative $C$ (T) method. Nat. Protoc. 3, 1101-1108 (2008).

51. O'Toole, G. A. Microtiter dish biofilm formation assay. J Vis Exp. 47, 2437. https:// doi.org/10.3791/2437 (2011).

Open Access This article is licensed under a Creative Commons Attribution 4.0 International License, which permits use, sharing, adaptation, distribution and reproduction in any medium or format, as long as you give appropriate credit to the original author(s) and the source, provide a link to the Creative Commons license, and indicate if changes were made. The images or other third party material in this article are included in the article's Creative Commons license, unless indicated otherwise in a credit line to the material. If material is not included in the article's Creative Commons license and your intended use is not permitted by statutory regulation or exceeds the permitted use, you will need to obtain permission directly from the copyright holder. To view a copy of this license, visit http://creativecommons. org/licenses/by/4.0/.

(c) The Author(s) 2019 